\title{
Pay for Performance - What are the options?
}

Pay for performance in some areas is already an integral part of our system, although not necessarily recognized as such. Structural and sometimes process requirements as minimum standards for medical services can be defined by different German authorities as a part of the legal requirements for the reimbursement of providers. Federal rules for readmissions within the DRG system also contain a negative P4P variant, i.e. nonpayment for certain complications.

However, P4P in a more narrow sense, as a modification of payments related to outcome measures, is not yet included in our system. New and sound outcome indicators have been developed during the last years $[1,2,4]$. Thus the question arises, if and how these might be included into the reimbursement system. The following options are discussed by the author:

\section{The „black sheep" problem}

$\nabla$

If highly relevant outcome indicators, like for example mortality, are measured, there are usually a few (less or far less than $5 \%$ ) providers, which show significantly bad outcome numbers, even if advanced risk adjustment is applied. The question of how to handle these cases involves two aspects:

(a) Politically it is questionable, if there are organisations, which are able to deal with this problem concerning the inevitable argument, that risk adjustment is insufficient and related legal obstacles in dealing with these problems.

(b) On the other hand, it must be questioned, if not acting can ethically be justified.

Concerning these opposing arguments and the patient risk involved, at least an inversion in the burden of proof should be considered for such cases: It should not be the burden of a payor or quality assurance body to ultimately prove that there is a failure, but in extreme cases the provider should be held responsible for proving, that he has no medical problems.

\section{Nonpayment for complications $\checkmark$}

Considering the fact, that complications are indirectly paid for as 'increased severity' via the CCrelated payment increases and other mechanisms in most DRG-systems, the new Medicare approach of excluding certain complications from being considered as 'severity increase' is a promising development [5]. However, as only few complications in medicine can be clearly classified as avoidable or largely reducable, if guidelines were followed, this approach is limited. Thus it can be seen as a supplement, which can be implemented in parallel to other options and should be embedded within a wider P4P-framework in the future.

\section{Non-contracting for certain services $\checkmark$}

The measurement of outcome indicators related to a certain disease or procedure (like for example myocardial infarction mortality or mortality for colorectal surgery) involves statistical problems. In a single hospital the case numbers will often be too low to prove significant differences against other providers. This may especially be true for smaller providers, for which quality problems may be shown for certain indicators on a group level in large studies [3], however cannot be proven on a single provider level due to statistical limitations. Due to these statistical uncertainties quality indicators for defined services will usually - in the wide $90 \%$-mid-range of providers - not be reliable enough for negotiating the complete exclusion or inclusion of certain services in reimbursement contracts. Only in rare cases as described under topic 1 . or in the opposite case of some large providers with very good outcome the numbers might become relevant for contracting.

\section{Including quality scoring systems into the reimbursement scheme $\nabla$}

In an approach to overcome the statistical uncertainties of single indicators, it might be decided to assign scores to every indicator, which are related to the degree of deviation against the national average. If statistical methods were applied, the degree of deviation can easily be combined with volume numbers, giving for example a high volume center with significantly good outcome a better score than a low volume hospital with the same, but more uncertain outcome numbers. Scores from single indicators may be added up to form a hospital score. This can be used to modify the standard payments. In the German DRG system a modification of the DRG base rate would be the choice. Such a modification can be limited for example to a range of $+/-2 \%$ of the total bud-
T. Mansky

Qualitätsmanagement

Keywords

outcome

pay for performance

quality indicators

\section{Schlüsselwörter \\ Ergebnisqualität \\ Ergebnisorientierte \\ Leistungsvergütung \\ Qualitätsindikatoren}

Institut

HELIOS Kliniken, Berlin

Bibliografie

DOI 10.1055/s-0029-1242680 Dtsch Med Wochenschr 2009; 134: S325-S326 - (c) Georg Thieme Verlag KG Stuttgart . New York · ISSN 0012-0472

Korrespondenz PD Dr. Thomas Mansky

Leiter Medizinische Entwicklung HELIOS Kliniken

Friedrichstr. 136

10117 Berlin

Tel. 030/521 321-140

eMail thomas.mansky@

helios-kliniken.de 


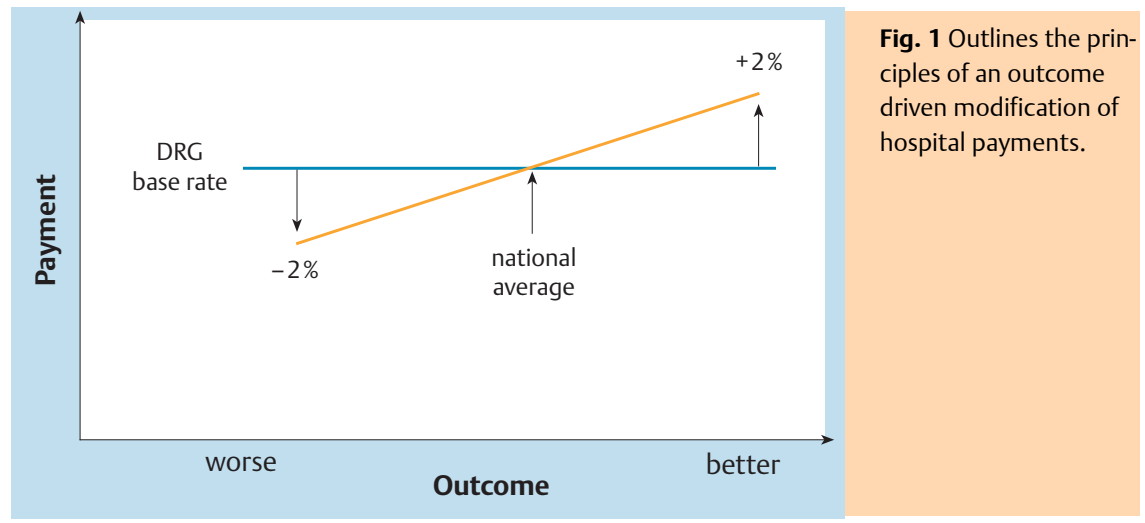

get. Unlike more radical approaches such a system would not fundamentally endanger the existence of a provider, which is a contribution to remaining statistical uncertainties of the method. However a system like this would introduce strong incentives for making medical outcome a management issue. It is well known from the German budget-oriented contracting system, that even small financial modifications have an effect on provider behaviour.

\section{Regional and national outcome goals}

Modern outcome indicators, especially long-term indicators $[2,4]$, are ideally suited for measuring regional and national outcome. The statistical uncertainties seen at the provider level are usually not a problem at this level. Outcome related health policy goals would make sense and could help to indentify health services problems and thus improve the overall system performance. Outcome at this level often cannot be related to a single provider, but might involve different services. In the case of 1-year heart failure mortality for example hospital as well as primary care services might be involved and patient compliance for example is also an important factor. However recent positive experience has shown, that quality management can influence outcome even in more complex cases (cf. for example [4] for experience within an organisation like Helios or the IHI campaigns under www.ihi.org). The definition of regional and national outcome goals would be a desirable development per se. It must not necessarily be part of a P4P approach, but could support the provider oriented approaches mentioned before.

\section{Conclusion}

The increasingly wider availibility of medical data within the administrative data sets due to DRG reimbursement methods and the development of outcome indicators based on such data have brought outcome oriented management and payment methods within reach. The most promising approach at the provider level might be a gradual score-based implementation of outcome oriented payments. On a regional and national level this could be supported by outcome related heath goals. Both steps - alone or in combination - could help to set the right incentives and to foster the development of outcome oriented management methods in medicine.

Autorenerklärung: Der Autor ist bei den Helios Kliniken für das Qualitätsmanagement zuständig.

\section{Literatur}

1 Agency for Healthcare Research and Quality. Inpatient Quality Indicators Overview. Rockville, MD: February 2006 http:// www.qualityindicators.ahrq.gov/ iqi_overview.htm

2 AOK-Bundesverband, Forschungs- und Entwicklungsinstitut für das Sozial- und Gesundheitswesen Sachsen-Anhalt (FEISA), HELIOS Kliniken, Wissenschaftliches Institut der AOK (WIdO). Qualitätssicherung der stationären Versorgung mit Routinedaten (QSR) - Abschlussbericht. Bonn: WIdO, 2007

3 Birkmeyer JD et al. Hospital volume and surgical mortality in the United States. N Engl J Med 2002; 346: 1128-1137

4 Busse R, Nimptsch U, Mansky T. Measuring, Monitoring, And Managing Quality In Germany's Hospitals. Health Affairs 2009Web exclusive DOI 10.1377/hlthaff.28.2.w294

5 Valuck T. Medicare Value-Based Purchasing: Non-Payment for Selected Hospital-Acquired Conditions. DMW 2008; 37: S140-S143 